\title{
El régimen impositivo para la microempresa en Cuba
}

\author{
Archibald R. M. Ritter \\ Departamento de Economía \\ y Escuela de Asuntos \\ Internacionales, \\ Carleton University, \\ Ottawa, Canadá \\ ArchRitter@pigeon.carleton.ca
}

Apenas legalizado el sector, en 1993, el gobierno de Cuba estableció un régimen impositivo para la microempresa. Fue diseñado para funcionar en un contexto difícil, caracterizado por la inexistencia de una cultura tributaria que hacía temer un incumplimiento generalizado y en él eran muy elevados los ingresos de algunos microempresarios. El régimen impositivo incluye pagos anticipados de cuota fija, un monto máximo de un $10 \%$ deducible de los ingresos totales como costos para el cálculo de la renta imponible, y una escala de impuestos progresiva. Sus muchas debilidades lo hacen injusto, ineficiente e ineficaz para la generación de recursos fiscales. El análisis que se efectúa en este trabajo indica que la incidencia real del impuesto es mayor que la escala tributaria oficial cuando los costos efectivos de producción superan el máximo deducible permitido del 10\% (en algunos casos hasta 100\% más). Los pagos de cuota fija se traducen en tasas impositivas marginales de $100 \%$ para los primeros niveles de ingreso, seguidas por una tasa de $0 \%$ hasta alcanzar el nivel de renta imponible en que los impuestos devengados según la escala se igualan al pago de cuota fija inicial. El régimen impositivo discrimina contra las microempresas con costos de insumos superiores al $10 \%$ de sus ingresos brutos. Es regresivo porque, hasta un nivel bastante significativo de ingresos netos efectivos, las microempresas con menores ingresos están afectas a tasas más altas. El sector de la microempresa enfrenta un régimen más gravoso que el que se le aplica al sector económico de empresas extranjeras y de sociedades de participación. Desde la perspectiva de la eficiencia en el uso de los recursos, el régimen impositivo restringe el ingreso de empresas nuevas al sector y empuja a algunas al cierre o a la clandestinidad, con lo que eleva los precios y reduce la producción, el empleo y la generación de ingresos. Por último, en la medida en que se abren menos negocios o las empresas pasan a la clandestinidad, quiebran o evaden impuestos, el gobierno pierde recaudación fiscal. Aquí se sugieren diversas modificaciones al régimen impositivo para superar estas debilidades. Estos cambios redundarían para Cuba en una mejor contribución del sector en materia de generación de empleo e ingresos, aumento de la producción a costos reales, precios más bajos y una mayor recaudación tributaria. 
I

\section{Introducción}

En septiembre de 1993 — sumida en la crisis económica producida por el fin de la relación especial con la ex Unión Soviética-Cuba liberalizó el trabajo por cuenta propia, legalizando muchas de las actividades económicas que los cubanos ya ejercían en la clandestinidad como parte de sus estrategias de sobrevivencia personal o familiar. Esto permitió que afloraran muchas actividades que antes se desarrollaban en el mercado negro y que proliferara la creatividad empresarial. De inmediato se hizo evidente la necesidad de un sistema impositivo que gravara los ingresos generados en el sector del trabajo por cuenta propia y, en septiembre de 1993, se adoptó un sistema impositivo que alcanzó vigencia plena en 1996.

El régimen impositivo, como se diseñó y puso en práctica, sin duda ha extraído recursos del sector para el fisco. No obstante, presenta muchas debilidades que reducen su equidad, vulneran la eficiencia en la asignación de recursos y limitan su viabilidad. El objeto de este estudio es analizar el impacto del régimen impositivo para la microempresa sobre i) la equidad en la distribución del ingreso, tanto dentro del sector como en el conjunto de la sociedad; ii) la eficiencia en la utilización de recursos, tanto en el propio sector como en al ámbito más vasto de la economía y la sociedad y iii) la viabilidad, eficacia y capacidad de sustentación de la recaudación tributaria para el gobierno. A partir del análisis y la evaluación del régimen impositivo para la microempresa surgen muchas observaciones de cómo podría modificarse para alcanzar más plenamente los objetivos de equidad, eficacia y viabilidad.

En la sección II de este artículo se analiza el origen, estructura y naturaleza del sector de la microempresa. En la sección III se hace una breve reseña del entorno regulatorio y de políticas en el que opera. En la sección IV se describe la naturaleza del régimen impositivo para la microempresa y la lógica de su diseño, a lo que se agrega el principal análisis cuantitativo de su funcionamiento. En la sección V se abordan los aspectos de equidad, eficacia y viabilidad del régimen impositivo, tanto a nivel de las microempresas individuales como del sector y de la economía y la sociedad globales. En la sección VI se presenta una serie de recomendaciones específicas para mejorar el régimen impositivo desde la perspectiva de estos tres criterios fundamentales. Por último, en la sección VII se resume la argumentación básica y se reiteran las principales conclusiones.

\section{II}

\section{El sector de la microempresa}

A pesar de la nacionalización de las empresas medianas y pequeñas en la ofensiva revolucionaria de marzo de 1968, subsistió un pequeño sector de trabajo por cuenta propia, principalmente en las áreas de servicios personales, transporte, artesanía y diversos tipos de manufacturas. En 1988, el número de microempresas no agrícolas registradas oficialmente era de 28 600, con 12800 empleados, lo que representaba el $1.8 \%$ del empleo total (CEE, 1988). La economía clandestina incluía también muchas actividades de microempresa, y siguió operando a gran escala en el período entre 1968 y 1993. Sin embargo, es prácticamente imposible estimar su tamaño. Durante ese período, el volumen de trabajo por cuenta propia clandestino creció con rapidez a medida que las estrategias de sobrevivencia familiares requerían ingresos reales más allá de los que proveía el empleo estatal, que se hacían progresivamente insuficientes para satisfacer las necesidades diarias que ya no podían atenderse a través del sistema de racionamiento (Ritter, 1998a, pp. 74-76).

La liberalización del trabajo por cuenta propia, el 8 de septiembre de 1993, permitió a muchos microempresarios volver de la economía clandestina y que nuevos empresarios se establecieran legalmente. El Decreto Ley 141 y la resolución que lo acompañaba legalizó 117 tipos de actividades en seis áreas genera- 
les, incluyendo transporte, reparación de viviendas, actividades relacionadas con la agricultura, servicios personales y familiares, servicios de vivienda y otras actividades. Hacia principios de 1997 se habían legalizado 157 tipos, incluyendo "servicios gastronómicos", que abarcaban ventas callejeras y restoranes privados o "paladares". La legislación de 1993 restringía el trabajo por cuenta propia a jubilados, dueñas de casa y trabajadores cesantes, pero excluía a profesionales y gerentes. A su vez, a los profesionales que eran declarados redundantes en sus actividades se les permitía ingresar a alguna de las categorías del trabajo por cuenta propia pero no como profesionales autoempleados. Para desempeñarse por su cuenta los trabajadores habituales del sector estatal necesitaban un permiso de su centro de trabajo. Como se verá más adelante, se impuso otra gran variedad de restricciones a la actividad de la microempresa.

El número de microempresas registradas aumentó rápidamente: llegó a 169098 en diciembre de 1994, y a un máximo de 208786 en diciembre de 1995 (cuadro 1). El nivel real de empleo era mayor que el número de microempresas ya que frecuentemente se empleaba a miembros de la familia, y otros a menudo abastecían de insumos a microempresas registradas. La Comisión Económica para América Latina y el Caribe (CEPAL, Sede Subregional de la CEPAL en México, 1997) estimaba el empleo privado total en 400000 personas - 9.4\% del total en 1996-, pero puede haber sido mayor.

Si se incluye el trabajo por cuenta propia informal, de jornada parcial, no registrado, el número de autoempleados puede llegar al $30 \%$ de la fuerza de trabajo, o más, ya que casi todas las familias en Cuba, excepto las que reciben transferencias de familiares $\mathrm{u}$ otras que tienen acceso a dólares (como del turismo extranjero, por ejemplo), deben suplementar sus ingresos salariales del Estado, que no alcanzan para las compras necesarias en los mercados agrícolas de mayor precio o tiendas en dólares, con ingresos adicionales de una actividad secundaria.

El trabajo por cuenta propia registrado y todas las demás actividades no registradas de autoempleo han hecho un aporte valioso a la economía y al pueblo cubanos: Han creado empleo y han ayudado a que las familias obtengan los ingresos necesarios para subsistir. Aunque algunas actividades de autoempleo han generado ingresos altos, la gran mayoría proporciona un ingreso suplementario, importante pero modesto. Ellas constituyen una escuela masiva de gestión empresarial, y también producen bienes y servicios básicos que satisfacen necesidades esenciales de casi todos los cubanos.

El sector genera también grandes volúmenes de recaudación para el Estado a través del sistema tributario y del cobro de multas, gravosas y al parecer frecuentes. El pago mensual de impuestos de un restorán del sector de tiendas en dólares (cuadro 2) alcanza a 520 dólares, ${ }^{1}$ lo que equivale a casi 50 veces el salario mínimo en el sector estatal (214 pesos en 1997) al tipo de cambio aplicable a los ciudadanos cubanos de 1 dólar por 20 pesos.

\footnotetext{
1300 dólares de pago básico mensual, más 100 dólares por una licencia de bebidas alcohólicas, más 60 dólares por cada uno de los empleados miembros de la familia, que como mínimo deben ser dos.
}

CUADRO 1

Cuba: Microempresas registradas (Número)

\begin{tabular}{|c|c|c|c|c|}
\hline & $\begin{array}{c}\text { Diciembre } \\
1994\end{array}$ & $\begin{array}{c}\text { Diciembre } \\
1995\end{array}$ & $\begin{array}{c}\text { Marzo } \\
1996\end{array}$ & $\begin{array}{c}\text { Enero } \\
1998\end{array}$ \\
\hline Aprobadas y registradas & 169098 & 208786 & 206824 & 159506 \\
\hline Solicitudes rechazadas & 10675 & 11519 & 12665 & (108 789) \\
\hline Solicitudes retiradas & 65586 & 148491 & 195023 & \\
\hline Solicitudes en proceso & 4193 & 21963 & 8789 & $\ldots$ \\
\hline
\end{tabular}

Fuente: Ministerio de Trabajo y Seguridad Social, de Cuba, y CEPAL, Sede Subregional de la CEPAL en México (1997). 


\begin{tabular}{|c|c|c|}
\hline & $\begin{array}{c}\text { Economía nacional } \\
\text { (pesos) }\end{array}$ & $\begin{array}{l}\text { Sector turismo } \\
\text { (dólares) }\end{array}$ \\
\hline Venta de alimentos y bebidas ("al detalle") & 100.00 & - \\
\hline Venta de alimentos casera & 200.00 & 100.00 \\
\hline Restoranes privados ("paladares") & 400.00 & 300.00 \\
\hline Venta de bebidas alcohólicas en restoranes privados & 100.00 & 100.00 \\
\hline Impuesto por mínimo de dos empleados miembros de la familia exigidos en restoranes privados & 120.00 & 120.00 \\
\hline
\end{tabular}

Fuente: Ministerio de Trabajo y Seguridad Social/Ministerio de Finanzas y Precios, 1995.

\section{III}

\section{El marco de políticas}

El régimen impositivo para las microempresas no es más que un elemento del entorno general de políticas en que se desenvuelven las microempresas.

El primer elemento del marco de políticas es el gran abanico de normas detalladas que afectan su tamaño y operación. El marco regulatorio incluye los siguientes aspectos generales que resume el Decreto Ley 174 (Gaceta Oficial, 1997):

- Prohibición de "intermediarios" de cualquier tipo: los productores deben vender su propio producto, los vendedores deben producir lo que venden sin revendedores especializados, sin mayoristas y sin que los productores puedan vender sus productos para que otros los vuelvan a vender.

- Prohibición del trabajo por cuenta propia en todas las áreas profesionales.

- Restricciones de acceso a los mercados, con prohibición de vender a todas las entidades estatales, a menos que se tenga autorización expresa para hacerlo.

- Prohibición de hacer publicidad.

- Inexistencia de acceso a créditos, a divisas al tipo de cambio oficial y a insumos de importación directa.

- Prohibición de contratar mano de obra fuera de la familia.

- Prohibición de asociación entre trabajadores por cuenta propia.

- Limitación adicional específica para restoranes privados; máximo 12 asientos.

- Adquisición de insumos sólo en tiendas en dólares o mercados agrícolas cuyos precios son va- rias veces superiores a los de los mismos insumos en el sector estatal; limitación de productos disponibles.

- Limitaciones adicionales específicas para la venta de alimentos en la calle: por ejemplo, prohibición del uso de bancos, sillas o mesas.

- Prohibición de usar como sede de la actividad de la microempresa cualquier lugar distinto de la casa familiar o, en algunos casos, un puesto de venta arrendado en un mercado.

Hay también diversas normas de salud, sanidad y condiciones de seguridad para "servicios gastronómicos" y transporte privado. Por supuesto, en tales áreas algunas de estas normas son necesarias. Sin embargo, la definición de los estándares aplicables parece no estar acotada, por lo que a fin de cuentas la norma exigida puede ser la que al inspector le parezca apropiada. El carácter de las multas y los castigos parece permitir la discrecionalidad de los inspectores en las sanciones por infracciones y en la intensidad con que las aplican (Gaceta Oficial, 1997). Para las 28 infracciones de carácter operacional económico de las microempresas, las multas pueden ser importantes -hasta 1500 pesos, equivalentes a cerca de siete veces el ingreso nacional medio mensual, aunque quizás no excesivamente onerosas para los tipos de autoempleo más lucrativos. Comparativamente, las infracciones de tránsito van desde alrededor de 2 pesos, por virar a la izquierda en lugar prohibido, hasta 10 pesos por una infracción grave como no detenerse ante una luz roja. La suspensión de la licencia de una microempresa infractora por un mínimo de dos años es, en 
muchos casos, un castigo severo que destruye la forma de vida del infractor y de su familia. Algunos propietarios de restoranes sostienen que la suspensión de la licencia es, en los hechos, permanente. El posible embargo de equipos, instrumentos, maquinarias o materiales significa la confiscación del capital acumulado por el microempresario, por poco que éste sea. Las infracciones múltiples o repetidas reciben castigos más severos. Si la multa no se paga en 30 días, se duplica. Si no se paga en 60 días, la autoridad competente está facultada para embargar sueldo, salario, pensión o cualquier otro ingreso, luego la cuenta bancaria, y luego cualquier propiedad mueble.

El cumplimiento de las normas está encargado a un cuerpo de inspectores que incluye tanto los que se ocupan de las normas económicas como los que velan por las de salud, seguridad, ambientales y laborales. Los inspectores pueden aplicar multas, embargar equipos y cancelar licencias en forma inmediata, cerrando una microempresa en cualquier momento, aparentemente sin muchas posibilidades de apelar con éxito

De estas normas deriva una gran variedad de consecuencias económicas. Primero, restringen el normal crecimiento y expansión de las microempresas individuales, condenándolas a un tamaño pequeño. Como resultado de ello los ingresos de los empresarios se limitan considerablemente. De esta forma se evita que las microempresas compitan seriamente con las empresas del sector estatal en algunas áreas como servicios de alimentación, transporte y taxis. Segundo, como resultado de las normas económicas, las microempresas operan en forma ineficiente. La prohibición de "intermediarios", por ejemplo, obliga a los artesanos o fabricantes de diversos productos no sólo a la venta cotidiana al detalle de sus productos, sino que a hacerse el tiempo para producir lo que venden, y no otros productos. De esta forma, la prohibición de detallistas especializados consume el tiempo de los artesanos reduciendo la cantidad y calidad de su producción. $\mathrm{O}$, más probablemente, alienta diversas infracciones a las normas en la operación diaria, pese al celo de los inspectores por hacerlas cumplir. El resultado global de las normas es, por lo tanto, desperdiciar las energías de muchos empresarios, bajar su productividad y reducir la calidad y cantidad de su producción. Así, el impacto general para Cuba es el malgasto de sus energías humanas, así como de su capital y sus recursos materiales.

Otro ámbito donde la política pública parece orientada a contener partes del sector de las microempresas es la competencia de las empresas estatales, que a menudo tienen costos de insumos que no son más que una pequeña fracción de los que tienen las microempresas (Ritter, 1998a).

El entorno político general en que ha operado el sector de la microempresa ha sido incierto desde su legalización en 1993. La legislación original incluía una cláusula que podía usarse en cualquier momento para eliminar partes del sector (Cuba, Gobierno, 1993). En un discurso de abril de 1997, Castro criticaba las reformas de 1993-1994, alegando que generaban ingresos diez, veinte, o hasta treinta veces superiores a lo que ganaba un trabajador y que se habían promulgado sin imaginar jamás que tendrían que aprender a vivir con ellas durante un tiempo difícil de predecir y que dependía de muchos factores (Castro, 1997). Esta afirmación se interpretó ampliamente como que la continuidad del sector de la microempresa estaba en peligro.

El sector de la microempresa es también criticado por la prensa que controla el Estado. Periódicamente han aparecido artículos con críticas al sector (Lee, 1996; Del Barrio, 1998; Mayoral, 1995 y 1997; y Ricardo, 1998). La prensa suele destacar las ilegalidades perpetradas por el sector, los supuestos altos ingresos que percibe, la evasión de impuestos y la aparente necesidad de velar por un cumplimiento más riguroso de la ley, aumentar la vigilancia y extremar los controles.

\section{IV}

\section{El régimen impositivo para la microempresa}

\section{Estructura del régimen impositivo}

El régimen impositivo para la microempresa se basa en el pago mensual de sumas fijas obligatorias a la autoridad tributaria - la Oficina Nacional de Administración Tributaria (ONAT) — junto con una corrección autoadministrada del pago de impuestos anuales que realiza cada microempresa. Característica esencial del 
sistema es el descuento máximo permitido de $10 \%$ del ingreso imponible por concepto de compras de insumos.

El primer elemento del régimen impositivo es la cuota fija mensual, que se estableció originalmente en 1993 cuando Cuba emprendió la primera fase de liberalización de la microempresa. Los ministerios de Finanzas y Precios y de Trabajo y Seguridad Social establecieron tasas mínimas, pero los Concejos Administrativos de los Gobiernos Municipales están facultados para establecer tasas sobre estos niveles mínimos con la aprobación de los ministerios respectivos. Las tasas pueden modificarse cada seis meses, en enero y en julio. La legislación permite a los Concejos elevar las tasas si considera que los ingresos de las microempresas son "excesivos", aunque no define este concepto (Cuba, Gobierno, 1993). Nuevamente, el carácter ambiguo de la ley aumenta la incertidumbre para las microempresas. La ley permite aumentos, pero no disminuciones de las tasas impositivas. Esto también se suma a la incertidumbre y anquilosa el sistema para el microempresario, quien debe pagar la cuota fija mensual completa, tanto en los meses buenos como en los malos. No obstante, el microempresario puede abandonar la actividad al comienzo de cualquier mes cesando inmediatamente los pagos mensuales.

Las tasas se establecieron a niveles relativamente bajos en septiembre de 1993, pero han ido subiendo persistentemente desde entonces. Destaca especialmente la distinción entre las microempresas que operan en la economía del dólar y las que lo hacen en la economía del peso, aplicándose a las primeras una tasa 20 veces superior a la de las últimas (al tipo de cambio aplicable para los cubanos).
La segunda característica del régimen impositivo es que a fin de cada año las microempresas deben pagar impuesto sobre sus ingresos, sobre la base de una escala progresiva. Sin embargo, pueden deducir del impuesto devengado según la tabla el total de pagos de cuota fija mensual. El procedimiento es como sigue:

i) las microempresas suman sus ingresos brutos;

ii) restan el $10 \%$ de los ingresos brutos $(20 \%$ en el caso del transporte privado) como deducción permisible por insumos comprados, para determinar el ingreso neto imponible;

iii) calculan el impuesto devengado según la escala que figura en el cuadro 3. Los pagos son acumulativos y cada tramo de ingreso es gravado a la tasa respectiva de cada tramo;

iv) deducen del impuesto devengado según la escala la suma de las cuotas fijas mensuales pagadas;

v) si el monto devengado según la escala excede del monto ya pagado en las cuotas fijas mensuales, el impuesto a pagar equivale a esta diferencia;

vi) si el monto devengado es inferior a lo ya pagado no reciben devolución del exceso de impuestos pagado.

La escala impositiva oficial (cuadro 3) incluye una escala para ingresos e impuestos en moneda nacional y otra para ingresos e impuestos en dólares o "pesos convertibles". La escala de impuestos se aplica al ingreso neto descontado el 10\% de ingresos brutos, máximo permitido para compras de insumos. La progresividad de la escala impositiva para ingresos en dólares no difiere mucho de los estándares internacionales. Parece también razonable desde la perspectiva cubana. Por otro lado, para ingresos en pesos la escala aumenta de 5\% para los primeros 3000 pesos hasta

CUADRO 3

Cuba: Escalas de impuestos aplicadas al ingreso personal

\begin{tabular}{|c|c|c|c|c|c|c|c|c|c|c|}
\hline & \multicolumn{5}{|c|}{ Escala para ingresos en pesos } & \multicolumn{5}{|c|}{ Escala para ingresos en dólares } \\
\hline & \multicolumn{3}{|c|}{$\begin{array}{c}\text { Tramo } \\
\text { de impuestos }\end{array}$} & \multirow{2}{*}{$\begin{array}{c}\text { Tasa del } \\
\text { impuesto }(\%)\end{array}$} & \multirow[t]{2}{*}{$\begin{array}{l}\text { Monto del } \\
\text { impuesto }\end{array}$} & \multicolumn{3}{|c|}{$\begin{array}{l}\text { Tramo de } \\
\text { impuestos }\end{array}$} & \multirow{2}{*}{$\begin{array}{c}\begin{array}{c}\text { Tasa del } \\
\text { impuesto }(\%)\end{array} \\
10\end{array}$} & \multirow[t]{2}{*}{$\begin{array}{l}\text { Monto del } \\
\text { impuesto }\end{array}$} \\
\hline a) & 0 & - & 3000 & & & 0 & - & 2400 & & \\
\hline b) & 3000 & - & 6000 & 10 & & 2400 & - & 6000 & 12 & \\
\hline c) & 6000 & - & 12000 & 15 & & 6000 & - & 9600 & 15 & \\
\hline d) & 12000 & - & 18000 & 20 & & 9600 & - & 13200 & 20 & \\
\hline e) & 18000 & - & 24000 & 25 & & 13200 & - & 18000 & 25 & \\
\hline f) & 24000 & - & 36000 & 30 & & 18000 & - & 24000 & 30 & \\
\hline g) & 36000 & - & 48000 & 35 & & 24000 & - & 36000 & 35 & \\
\hline h) & 48000 & - & 60000 & 40 & & 36000 & - & 48000 & 40 & \\
\hline \multirow[t]{2}{*}{ i) } & 60000 & & y más & 50 & & 48000 & - & 60000 & 45 & \\
\hline & & & & & & 60000 & & y más & 50 & \\
\hline
\end{tabular}

Fuente: ONAT (1997, p. 1); Ministerio de Finanzas y Precios (1996). 
alcanzar a 50\% para el tramo de impuestos de ingresos superiores a 60000 pesos. La escala impositiva en pesos sí parece excesiva, ya que la tasa impositiva marginal del 50\% se aplica a un ingreso anual de 60000 pesos, equivalente a cerca de 3000 dólares.

Como tercera característica, el sistema tributario permite una deducción máxima del $10 \%$ del ingreso bruto por compra de insumos en la determinación del ingreso imponible. En otras palabras, se considera siempre que el ingreso neto para fines tributarios o "ingreso imponible" es el 90\% del ingreso bruto, cualquiera que sea el valor real de las compras de insumos. La única excepción está en el transporte, donde la deducción máxima por compra de insumos es $20 \%$ (ONAT, 1997, p. 6). Aquí lo llamaremos "regla del $10 \%$ de costo máximo descontable". El problema de esta característica del sistema tributario es que aquellas microempresas que tienen altos costos de insumos están, de hecho, siendo gravadas por esas compras. Esto quiere decir que la tasa impositiva efectiva sobre el valor agregado por la empresa en sus ingresos netos reales puede ser mucho más alta que las que se aprecian en el cuadro 3, que muestra las tasas efectivas para una microempresa con costos de insumos reales equivalentes al $10 \%$ de sus ingresos brutos.

¿Qué proporción de las microempresas tienen ingresos netos iguales o superiores a sus ingresos brutos? Es probable que la proporción sea importante. Muchas microempresas conjugan actividades que hacen uso intensivo de trabajo con equipamiento o compras de insumos materiales mínimos. Las siguientes microempresas pueden ser de este tipo: mensajero, guardia de bicicleta, cuidado de niños, guardia de edificio, manicurista, masajista, reparador de calzado, servicio doméstico, instructor deportivo o de idiomas, y algunos servicios de reparación. Por otro lado, otras actividades (como venta de alimentos, zapateros, artesanos, cultivadores y vendedores de flores, vendedores de libros y discos usados) deben comprar y procesar cantidades importantes de insumos materiales. Operadores de restoranes privados estiman su costo de insumos en más de 60\% (Ritter, 1998b).

\section{La lógica del actual sistema impositivo}

Hay tres factores que explican la adopción de este régimen impositivo. Primero, cuando se legalizó el trabajo por cuenta propia en septiembre de 1993, los precios, los ingresos y las utilidades netas eran a menudo muy altas. Ello se debía al exceso de poder adquisitivo en manos de la población (porque el gobier- no estaba financiando un gran déficit - cerca del $28 \%$ del PIB en 1993- mediante la creación de dinero, mientras los precios en el sector estatal permanecían fijos a niveles bajos) y también a la reducida cantidad inicial de microempresas. La implantación del régimen impositivo y la progresividad de las tasas se diseñaron, por razones de equidad, para extraer una proporción sustancial de este ingreso. Debe destacarse nuevamente, sin embargo, que la mayoría de las microempresas se dedican a producir bienes y servicios simples para cubanos de ingresos bajos en la economía del peso, y generan ingresos modestos, aun cuando probablemente sean más altos que el promedio del sector estatal.

Segundo, el régimen impositivo para las microempresas se estableció en un momento en que aún no existía una administración consolidada para este tipo de tributación. Tampoco existía un sistema impositivo transparente ni el hábito popular de pagar impuestos, porque antes las tasas de impuestos y los pagos se aplicaban en forma encubierta. Más aún, antes de la legalización de la microempresa, muchas de ellas habían funcionado en la clandestinidad, evadiendo pagos de impuestos y otros tipos de normas. El sistema tributario puesto en práctica parece haber sido diseñado para lograr un alto nivel de cumplimiento en un contexto donde la norma había sido el desacato (en la economía informal) y donde no había una práctica establecida de pagar impuestos no encubiertos.

Tercero, era considerable el volumen de robo de productos en el sector estatal de la economía, especialmente en el decenio de 1990. Parte de ellos llegaban al sector de la microempresa como insumos productivos. Uno de los elementos novedosos del sistema impositivo -el límite de $10 \%$ de deducción del ingreso imponible por compras de insumos- parece haber sido diseñado para manejar esta situación. Si era imposible saber con certeza el valor efectivo de los insumos comprados, era peligroso permitir que las microempresas calcularan sus propios costos de insumos para determinar el ingreso imponible. Era más fácil aplicar, por la vía administrativa, en todas las microempresas, un máximo de $10 \%$ del ingreso bruto como compra de insumos sin importar cuál fuese el valor real de estas compras.

Una idea popular entre los "cuentapropistas" es que el sistema tributario se diseñó para castigarlos por razones ideológicas y, a la larga, para llevarlos a la quiebra. Esto es posible, y hay declaraciones de los líderes políticos que parecen avalar esta visión. La avalan también el uso excesivo de las reglamentaciones y 
los severos castigos por infracciones. No es probable que el actual régimen impositivo para la microempresa haya sido diseñado para liquidar al sector, sino más bien para recaudar impuestos en un medio difícil, en que el pago abierto y transparente de impuestos no era una práctica establecida.

\section{Un análisis cuantitativo del régimen impositi- vo para la microempresa}

El análisis del régimen impositivo para la microempresa presenta dos complicaciones: primero, el impuesto anticipado de cuota fija, y segundo, el requisito de la ley de impuesto a la renta de fijar el ingreso neto imponible en un $90 \%$ del ingreso bruto. Para estudiar las consecuencias de estos factores en el régimen impositivo para la microempresa se efectúa aquí un análisis paso a paso. Primero, se presenta una breve sección donde se deriva matemáticamente la relación entre i) la tasa impositiva "efectiva" y ii) el valor agregado por la microempresa (o alternativamente el valor de los insumos comprados como porcentaje del ingreso total). Los efectos de los pagos de cuota fija combinados con la escala impositiva se analizan entonces mediante una presentación gráfica.

La relación entre la tasa impositiva "efectiva" que grava a una microempresa y el valor de los insumos comprados por ella (su valor agregado neto) se analiza aquí, partiendo con la derivación matemática de dicha relación y utilizando las definiciones siguientes:

$c$ : $\quad$ Porcentaje del ingreso bruto usado para compras de insumos.

$G Y: \quad$ Ingreso bruto

GYk(1-0.1): Tramos de impuestos determinados oficialmente

GYk(1-c): $\quad$ Valor agregado efectivo o ingreso neto para el tramo de impuestos

NYk: Ingreso imponible para el tramo de impuestos

TNYk: Ingreso neto efectivo para el tramo de impuestos

$T k$ : $\quad$ Tasa de impuesto para el tramo de impuestos específico

Mk: $\quad$ Monto del impuesto pagado en el tramo de impuestos

NAYk: $\quad$ Ingreso neto después de impuestos en el tramo de impuestos

$V k=M k / T N Y k:$ Tasa de impuesto como \% del ingreso neto efectivo en el tramo de impuestos
El ingreso neto efectivo se define como el ingreso bruto menos el costo de los insumos adquiridos, es decir, el valor agregado neto:

$$
T N Y k=G Y k^{*}(1-c)
$$

El ingreso imponible se define por la legislación tributaria como el ingreso bruto menos un $10 \%$ imputable a compras de insumos (cualquiera sea el valor real de esas compras), es decir, siempre se considera que el valor agregado neto para fines tributarios equivale al 90\% del ingreso bruto:

$$
N Y k=G Y k^{*}(1-0.1)=G Y k^{*} 0.9
$$

El monto del impuesto a pagar surge entonces de la multiplicación de la tasa de impuesto en el tramo de impuestos respectivo por el ingreso imponible para ese tramo:

$$
M k=(T k / 100) * N Y k
$$

De [2],

$$
G Y k=N Y k / 0.9
$$

Y, sustituyendo [4] en [1],

$$
\begin{gathered}
T N Y=(N Y / 0.9) *(1-c) \\
\text { o, TNYk }=(N Y k / 0.9) *(1-c)
\end{gathered}
$$

De esta forma, dado un valor de $c$, para cada valor de $N Y k$ existe un valor correspondiente de $T N Y \mathrm{k}$ :

$$
V k=M k / T N Y k
$$

Es decir, la tasa impositiva real equivale al monto pagado dividido por el ingreso neto efectivo para cada tramo de impuestos.

Entonces, sustituyendo [3] en [7]:

$$
V k=\{(T k / 100) * N Y k\} / T N Y k
$$

Nuevamente, sustituyendo [6] en [8],

$$
\begin{gathered}
V k=\{(T k / 100) * N Y \mathrm{k}\} /(N Y \mathrm{k} / 0.9) *(1-c) \\
0, V k=\frac{(T k / 100) * 0.9}{(1-c)}
\end{gathered}
$$


Utilizando la relación de la ecuación [9], se ajusta la escala impositiva oficial de la ONAT que aparece en el cuadro 3 para que represente las tasas impositivas efectivas sobre el ingreso neto efectivo. Se construye el cuadro 4, cuya sección A muestra los tramos de impuestos revisados en función del ingreso neto y las

Cuba: Cálculo de tasas impositivas para ingresos netos efectivos con distintos niveles de compras de insumos (o valor agregado neto)

\section{A. Siendo c las compras de insumos como \% del ingreso bruto}

\begin{tabular}{|c|c|c|c|}
\hline & \multicolumn{2}{|c|}{$\begin{array}{c}\text { Tramos de impuesto como ingreso neto efectivo } \\
\text { (pesos) }\end{array}$} & \multirow[t]{2}{*}{$\begin{array}{l}\text { Tasa de impuesto para } \\
\text { ingreso neto efectivo }(\%)\end{array}$} \\
\hline & Desde & Hasta & \\
\hline a) & & $3000 \times(1-c)^{(-1)} 0.9$ & $0.05 \times(1-c)^{(-1)} 0.9$ \\
\hline b) & $3000 \times(1-c)^{(-1)} 0.9$ & $6000 \times(1-c)^{(-1)} 0.9$ & $0.10 \times(1-c)^{(-1)} 0.9$ \\
\hline c) & $6000 \times(1-c)^{(-1)} 0.9$ & $12000 \times(1-c)^{(-1)} 0.9$ & $0.15 \times(1-c)^{(-1)} 0.9$ \\
\hline d) & $12000 \times(1-c)^{(-1)} 0.9$ & $18000 \times(1-c)^{(-1)} 0.9$ & $0.20 \times(1-c)^{(-1)} 0.9$ \\
\hline e) & $18000 \times(1-c)^{(-1)} 0.9$ & $24000 \times(1-c)^{(-1)} 0.9$ & $0.25 \times(1-c)^{(-1)} 0.9$ \\
\hline f) & $24000 \times(1-c)^{(-1)} 0.9$ & $36000 \times(1-c)^{(-1)} 0.9$ & $0.30 \times(1-c)^{(-1)} 0.9$ \\
\hline g) & $36000 \times(1-c)^{(-1)} 0.9$ & $48000 \times(1-c)^{(-1)} 0.9$ & $0.35 \times(1-c)^{(-1)} 0.9$ \\
\hline h) & $48000 \times(1-c)^{(-1)} 0.9$ & $60000 \times(1-c)^{(-1)} 0.9$ & $0.40 \times(1-c)^{(-1)} 0.9$ \\
\hline i) & $60000 \times(1-c)^{(-1)} 0.9$ & & $0.50 \times(1-c)^{(-1)} 0.9$ \\
\hline
\end{tabular}

\section{B. Siendo $c=10 \%$}

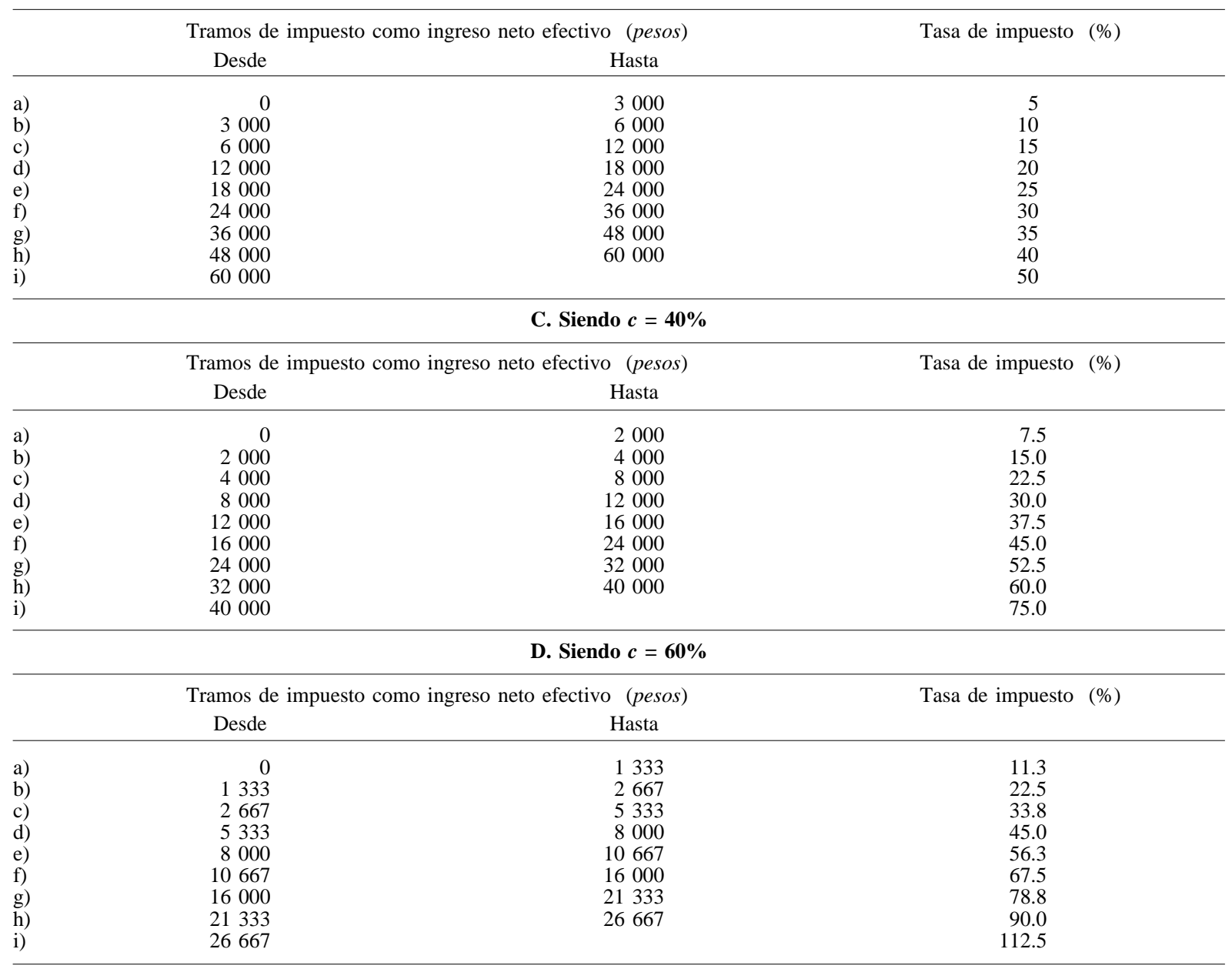

Fuente: La sección A se basa en la ecuación [9] y el cuadro 3. Los cálculos de las secciones B, C y D se basan en la sección A. 
tasas de impuesto efectivas como proporción del ingreso neto efectivo. Entonces, si se asignan valores distintos a $c$, se obtienen distintas tasas y tramos de impuestos. En el cuadro 4 se presentan las escalas y tasas de impuestos revisadas para valores de $c$ de $10 \%$, $40 \%$ y $60 \%$.

En el cuadro 4 se puede apreciar el rápido incremento de la tasa impositiva marginal efectiva. En el caso de un valor agregado neto efectivo de $40 \%$ (es decir, $c=0.6$ ) el tramo más elevado alcanza a $112.5 \%$. Esto ocurre en el tramo i), a un nivel de ingreso imponible de 60000 pesos o 26667 pesos de ingreso neto efectivo.

Si se eliminara la "regla del 10\%" y todas las microempresas dedujeran del ingreso imponible sus costos reales por compras de insumos, la escala impositiva oficial representaría el gravamen efectivo del sistema tributario para el microempresario. Como está, sin embargo, la escala oficial subestima la carga tributaria de todas aquellas microempresas que adquieren insumos por más del $10 \%$ de su ingreso bruto.

Los pagos del impuesto de cuota fija pueden analizarse usando los tres casos que se presentan en las secciones B, C y D del cuadro 4, con compras de insumos del $10 \%, 40 \%$ y $60 \%$ del ingreso bruto respectivamente. Estos casos se ilustran en los gráficos 1,2 y 3 . El tercer caso se explica en detalle y se hace tan sólo una breve referencia a los otros dos.

En el gráfico 3, con el ingreso bruto en la abscisa y el porcentaje de ingreso bruto en la ordenada, la línea horizontal al nivel de $60 \%$ indica que el gasto en insumos equivale al $60 \%$ del ingreso bruto. Entonces, el valor agregado efectivo corresponde al $40 \%$ del

GRAFICO 1
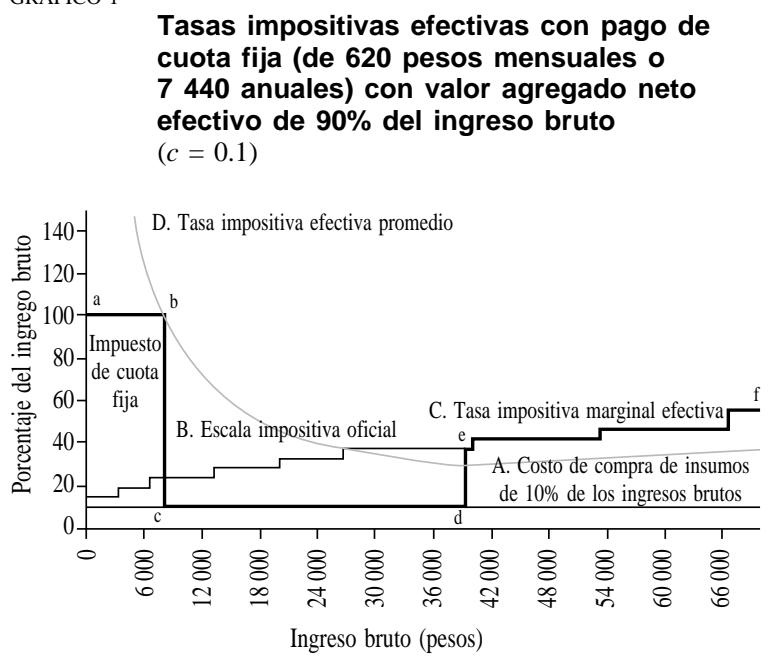

GRAFICO 2

Tasas impositivas efectivas con pago de cuota fija (de 620 pesos mensuales 07440 anuales) con valor agregado neto efectivo de $60 \%$ del ingreso bruto $(c=0.4)$

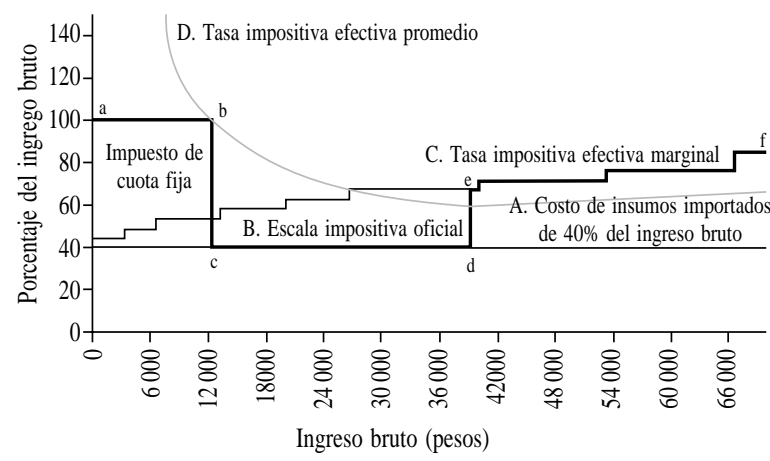

GRAFICO 3

Tasas impositivas efectivas con pago de cuota fija (de 620 pesos mensuales o 7440 anuales) con valor agregado neto efectivo de $40 \%$ del ingreso bruto $(c=0.6)$

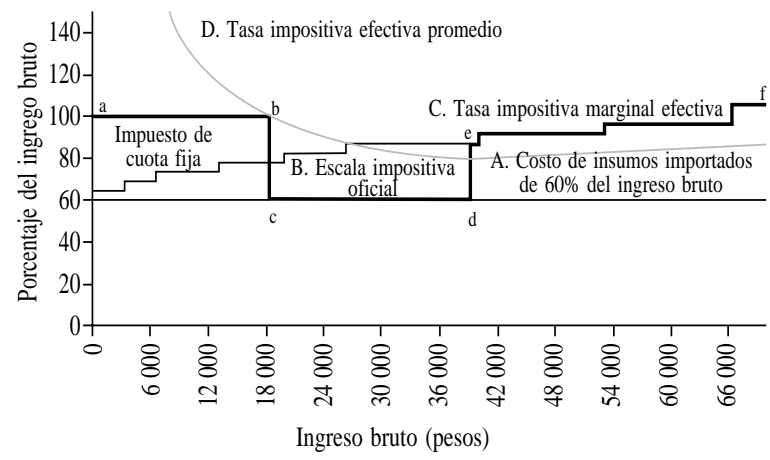

ingreso bruto que está sobre dicha línea. Las tasas impositivas marginales progresivas para los tramos de impuesto secuenciales están representadas por la función de tasas impositivas de forma escalonada. El área entre esta función y la línea del $60 \%$ representa el impuesto devengado por la microempresa, mientras que el área entre la función de tasa impositiva y la línea del 100\% representa el ingreso neto después de impuestos que retiene la microempresa. Puede apreciarse que la función de tasa impositiva asciende rápidamente y supera el $100 \%$ en el último tramo de impuestos (66 666.67 pesos por año o más). Este ascenso rápido se debe al hecho de que la tasa se aplica sobre el $90 \%$ de los ingresos brutos, aunque el microempresario sólo recibe el $40 \%$ como ingreso neto.

La complicación adicional surge porque el microempresario debe pagar el impuesto de cuota fija por 
anticipado. Consideremos el ejemplo de un restorán privado en la economía del peso. Para el caso, en base anual, el monto del impuesto de cuota fija podría ser de 620 pesos mensuales ( 7440 pesos por año): 400 pesos de cuota fija más 100 pesos de "impuesto de alcoholes" más 120 pesos por un mínimo de dos trabajadores registrados (cuadro 2). El área que representa el impuesto de cuota fija en el gráfico 3 muestra que se necesita un ingreso bruto de 18600 pesos a fin de generar ingresos netos suficientes $(40 \%$ del ingreso bruto) para pagar el impuesto. No obstante, del impuesto devengado según la escala de impuestos pueden deducirse los impuestos de cuota fija ya pagados. Esto significa que no es necesario pagar impuestos adicionales mientras el total del impuesto a pagar según la escala no alcance el volumen de los impuestos de cuota fija. En este caso el nivel de ingreso bruto que iguala los impuestos devengados con los pagos de cuota fija es de 39743 pesos, en el punto $e$.

La coexistencia del impuesto de cuota fija que puede ser deducido del impuesto devengado según la escala impositiva produce un curioso padrón de tasas impositivas marginales. Contrario a la imagen escalonada de la función impositiva, la función de tasa impositiva marginal efectiva (TIM) sigue la línea abcdef. Para los primeros 18600 pesos de ingreso bruto la тім del ingreso neto es $100 \%$. (Esta es una TIM, por cuanto dentro de este rango de ingreso bruto la microempresa debe pagar en impuestos, sobre una base mensual, el $100 \%$ de su ingreso neto). Sin embargo entre $c$ y $d$, la тім cae a $0 \%$ pues en este tramo de ingresos no es necesario pagar impuesto adicional: está cubierto con el impuesto de cuota fija. Sólo a partir del punto $e$, en que el ingreso supera los 39743 pesos, la escala vuelve a ser efectiva.

Este padrón de tasa impositiva marginal no puede dejar de afectar el comportamiento de la microempresa, y de varios modos. Cuando se incluye el impuesto de cuota fija en el gráfico 3, puede apreciarse que los ingresos netos después de impuestos incluyen en este caso sólo el área entre la línea del 100\% y la línea $b c d e f$. Parecen reducidas las posibilidades de que la microempresa genere ingresos netos suficientes para sobrevivir.

Los cálculos para el caso que ilustra el gráfico 3 se muestran en el cuadro 5. Ahí, la columna 1 muestra los tramos de impuestos definidos por el ingreso bruto menos la deducción permitida del $10 \%$ por compras de insumos. La columna 2 muestra entonces el ingreso bruto efectivo relevante para los tramos de impuestos. En la columna 4 se presenta el ingreso neto efectivo por cada tramo de impuestos, suponiendo un $60 \%$ de costo de insumos. Con las tasas de impuestos de la columna 5 se calculan los montos de impuesto

CUADRO 5

\section{Cuba: Cálculo para determinar las tasas impositivas reales con ingreso neto efectivo del $\mathbf{4 0} \%$ del ingreso bruto ${ }^{a}$ $(c=60 \%)$}

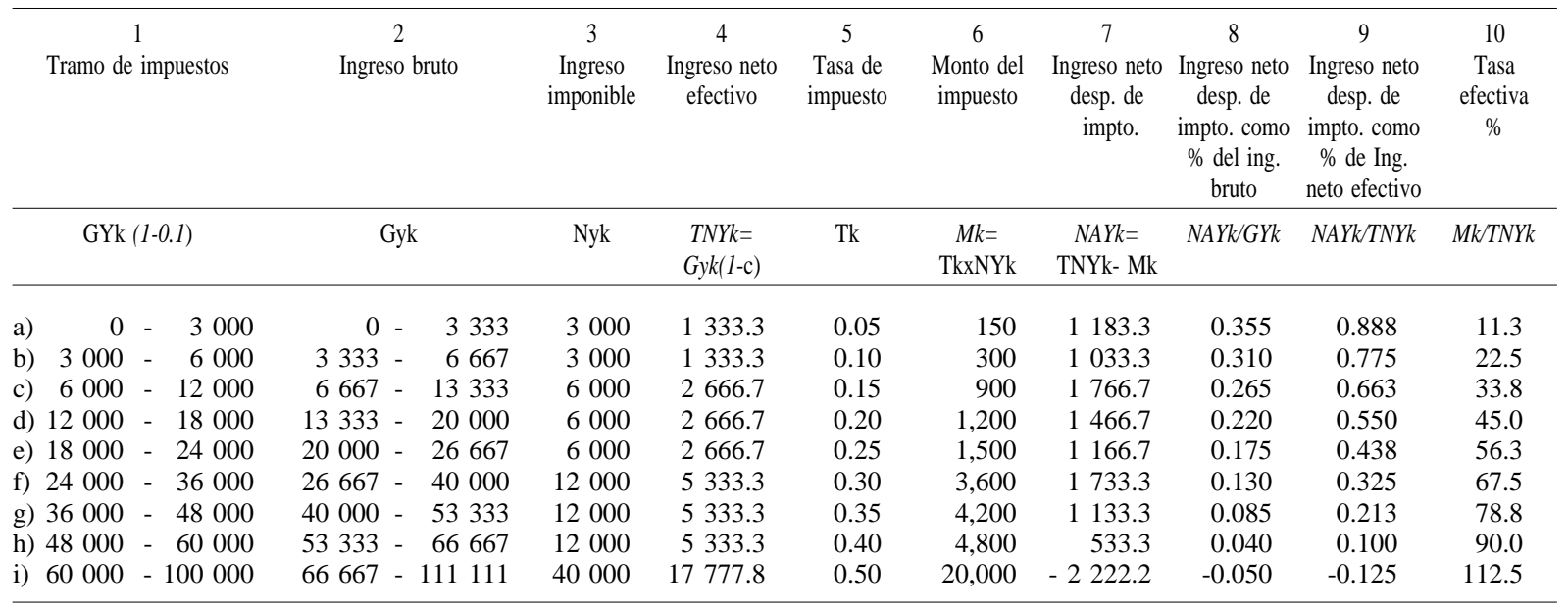

Fuente: Cálculos del autor.

a Supuesto: $c=0.6$, es decir, las compras de insumos equivalen al $60 \%$ del ingreso bruto. Véase las definiciones de los términos en la página 152. 
de la columna 6 , destacándose que lo realmente gravado es el ingreso bruto (menos el 10\% de costo de insumos). El monto del impuesto calculado de la columna 6 se presenta entonces como proporción del ingreso neto efectivo (de la columna 4) para determinar la tasa impositiva efectiva de la columna 10. En la columna 7, el ingreso neto después de impuestos se calcula como el ingreso neto efectivo menos el monto de impuesto pagado (columna 6). Luego, se calcula el ingreso neto después de impuestos, en la columna 8 , primero, como porcentaje del ingreso bruto primitivo (de la columna 2) y, segundo, en la columna 9, como porcentaje del ingreso neto efectivo. (En este cuadro no se incluyen las complicaciones de los pagos de cuota fija).

En este caso, la progresión de las tasas marginales como proporción del ingreso neto efectivo es dramática. Con un ingreso neto efectivo igual a tan solo el $40 \%$ del ingreso bruto, la escala de impuestos alcanza rápidamente niveles altos. Hacia el octavo tramo de impuestos, el 96\% de cada peso ganado se destina a proveedores de insumos o al fisco. En el último tramo, el monto del impuesto alcanza al $112.5 \%$ del ingreso neto efectivo, y el ingreso neto después del pago de impuestos es negativo.

En el gráfico 2 se ilustra el caso de compras reales de insumos de $10 \%$. Este caso no presenta complicaciones ya que el ingreso neto efectivo es igual al ingreso imponible permitido por la escala tributaria oficial de la legislación impositiva, que permite deducir un $10 \%$ del ingreso bruto por compras de insumos. En este caso las tasas de impuesto aplicadas por la escala impositiva son, de hecho, las mismas que las tasas impositivas para el ingreso neto efectivo. En el gráfico 2 se presenta un caso intermedio, en que las compras de insumos constituyen el $40 \%$ del ingreso bruto.

Sin recurrir a más casos, se puede concluir que mientras mayor sea el nivel de insumos que compra la microempresa (en otras palabras, menor sea el valor agregado neto efectivo de la empresa) más onerosa es la carga tributaria efectiva. Las tasas impositivas no parecen anormales para aquellas empresas con compras de insumos cercanas al 10\% (ingreso neto efectivo o valor agregado como proporción del ingreso bruto de un $90 \%$ ) y especialmente para aquellas con niveles de compras de insumos aún más bajos. Sin embargo, a medida que el nivel de valor agregado o de ingreso neto efectivo, como proporción del ingreso bruto, declina, las tasas impositivas promedio comienzan a aumentar rápidamente y llegan a ser imposibles.

Cuando se incluye en el análisis el impuesto de cuota fija la tasa impositiva promedio (TIP) es alta al principio, reflejando el carácter anticipado de este pago. (La función TIP está medida desde la línea de costo hacia arriba.) Como puede apreciarse en los gráficos 1,2 y 3 , la tasa impositiva media cae hasta donde la tasa impositiva oficial se hace efectiva, en el punto $e$ de cada gráfico. La TIP tiene especial relevancia como medida de la carga del impuesto, ya que expresa qué porcentaje del ingreso bruto se paga en impuestos (desde la línea de costos hacia arriba). De esta forma la tasa impositiva promedio y la tasa impositiva marginal decrecientes indican regresividad en la incidencia del sistema tributario: es decir, que el impuesto es más alto para los que perciben menos ingresos y decrece a medida que el ingreso aumenta hasta el punto $e$ de los gráficos.

Una última característica del impuesto de cuota fija no ilustrada en los gráficos es que a medida que el pago del impuesto de cuota fija aumenta en magnitud, el punto a partir del cual se hace efectiva la escala impositiva oficial se desplaza hacia la derecha en los gráficos 2 y 3 . Esto significa que a medida que los pagos de cuota fija aumentan el sistema impositivo se hace más regresivo. La estructura es regresiva desde el principio con tasas impositivas más altas para ingresos más pequeños.

\section{$\mathrm{V}$}

\section{Efectos sobre la equidad, la eficiencia}

\section{y la viabilidad}

El régimen impositivo para la microempresa tiene una serie de consecuencias sobre la igualdad, la eficiencia del sistema económico y la propia viabilidad del sis- tema de recaudación. Se exploran aquí estos efectos a nivel de la microempresa, del sector de la microempresa y de la sociedad y la economía cubanas. 


\section{En la microempresa}

Primero, los pagos de cuota fija significan una tasa impositiva marginal del $100 \%$ de los ingresos netos efectivos hasta que se genera el nivel de ingreso al cual la tasa impositiva marginal cae a $0 \%$ (punto $c$ en los gráficos 1,2 y 3 ). Esta tasa de $0 \%$ prevalece hasta que el ingreso bruto alcanza el nivel al que los pagos de impuestos devengados según la escala oficial - aunque deducibles de los pagos de cuota fija- se hacen iguales al total de pagos de cuota fija. En este punto ( $e$ en los gráficos) la escala impositiva oficial se hace efectiva nuevamente.

Enfrentada a este patrón de tasas impositivas marginales, la microempresa probablemente tratará de evitar el pago de las tasas superiores. Tratará de ubicarse en el punto $d$ de los gráficos 1,2 y 3 , el de mayores ingresos con una tasa marginal de $0 \%$, y tratará de generar ingreso bruto justo debajo de $d$. Esto revestirá especial importancia para las microempresas que enfrentan niveles de compras de insumos elevados (caso del gráfico 3), donde la tasa marginal salta, en el punto $e$, de $0 \%$ a $67.5 \%$. Lo puede hacer restringiendo su producción a este punto o declarando ingresos menores a los reales. Si la empresa restringe su producción, la sociedad pierde los bienes y servicios no producidos, el sector de la microempresa pierde ingresos y el gobierno pierde recaudación tributaria. Por otro lado, la microempresa puede también declarar menores ingresos y en este caso el gobierno pierde igualmente recaudación tributaria.

Con la elevada barrera de entrada que introduce la tasa impositiva marginal inicial del $100 \%$, algunas microempresas pueden no registrarse y decidir funcionar en la clandestinidad. No cabe duda de que esto ha ocurrido en Cuba. Muchos comerciantes se dedican a reparaciones de hogares; dueños de autos privados proporcionan servicios ocasionales de taxi, a pesar de los riesgos; dueñas de casa arriendan alojamiento extraoficialmente; y mucha gente provee servicios personales oficiosamente. En este caso el gobierno pierde recaudación. Aún más, puede perder su base tributaria si el número de microempresas disminuye.

La administración tributaria está consciente de las pérdidas de recaudación y utiliza inspectores y a los Comités de Defensa de la Revolución (CDR) para tratar de evitar que las empresas funcionen en la economía paralela. Sin embargo, la microempresa clandestina se ha generalizado y los miembros de tales comités (que incluyen a la mayoría de la población) están también involucrados en la economía paralela, lo que hace su control más difícil.
A pesar de la aparente progresividad de la escala impositiva oficial, la estructura tributaria es, de hecho, regresiva para las microempresas de ingresos medios y bajos. Como el impuesto de cuota fija crea una tasa impositiva marginal del $100 \%$ para el primer monto de ingreso ganado, seguido por una tasa marginal de $0 \%$, los ingresos netos relativamente más bajos de este rango están afectos a una mayor carga tributaria que los ingresos más altos. La tasa impositiva promedio decae a medida que el ingreso aumenta hasta el nivel en que se hace efectiva la escala oficial (punto $e$ en los gráficos). Este resultado es inequitativo porque los ingresos más bajos tienen una carga tributaria mayor que los ingresos más altos en este rango.

\section{En el sector de las microempresas}

El régimen impositivo es inequitativo en cuanto a sus efectos entre las microempresas. Debido a la regla de deducción máxima del $10 \%$ de los costos, las empresas con mayores niveles de compras de insumos pagan tasas de impuesto marginales y promedios más altos con relación a su ingreso neto que otras empresas de iguales ingresos netos pero con niveles de compras inferiores. Un segundo elemento de injusticia es la discriminación de la estructura tributaria contra las empresas nuevas de cualquier segmento del sector, porque la tasa impositiva marginal es inicialmente $100 \%$ por la cuota fija mensual. Las empresas nuevas deben generar ingresos inmediatamente para poder pagar estos impuestos. Es probable que las microempresas ya establecidas hayan alcanzado niveles de ingresos que les permitan acceder al rango de ingresos netos en que la tasa impositiva marginal es $0 \%$. De esta forma tienen una ventaja que las protege en parte de la nueva competencia, ayudando a mantener fuera a las empresas nuevas.

Desde la perspectiva del sector de la microempresa, el régimen impositivo genera una serie de ineficiencias. Al crear una alta barrera de entrada por la tasa de impuesto marginal del $100 \%$, se reduce el número de empresas que entran al sector. Los altos niveles de incertidumbre y riesgo para los nuevos entrantes sirven también de barrera para mantener fuera a los posibles nuevos participantes. Por lo tanto puede haber menos competencia legal, precios más altos y volúmenes de producción menores que los que habría si estas barreras fuesen más bajas. Además, para algunos otros tipos de microempresa a los que es más fácil entrar a la economía clandestina, el resultado puede ser una mayor competencia de productores de bienes y servicios que tienen costos menores que evadir en impuestos. 
La "regla del 10\%" también perjudica la eficiencia. Como resultado de los altos niveles de tributación efectiva para las microempresas que tienen mayores niveles de compra de insumos, el volumen de su producción de bienes y servicios es, probablemente, mucho menor. Los precios de sus productos son también anormalmente altos, producto de la elevada carga tributaria, pero sin reflejar necesariamente la eficiencia real y los costos efectivos de producción de dichas empresas.

Hay un efecto negativo adicional de "la regla del 10\%". Habitualmente la evolución de la economía genera una creciente articulación de la producción entre las empresas, a medida que se especializan y que el comercio entre empresas se expande. Con "la regla del $10 \%$ " se establece un desincentivo para que la microempresa adquiera insumos de otras empresas por lo draconiano del tratamiento tributario que se les da. Como resultado, las empresas evitan adquirir insumos de otras empresas. En el ámbito de la economía global esto equivaldría a detener el desarrollo de la especialización y el comercio entre ellas.

\section{En la sociedad}

La tributación del sector de la microempresa es necesaria, desde el punto de vista de la equidad. El sector, como todos los demás, debe pagar su porción de los costos de bienes y servicios públicos. Era difícil adivinar el nivel de tributación justo para el sector cuando estaba en vías de establecerse. Ello porque, al me- nos transitoriamente, los ingresos del sector fueron altos por muchas razones que se mencionan en la sección IV, subsección 2. Las elevadas tasas impositivas reales -en relación con los ingresos netos efectivos del sector- reflejaban el deseo de gravar esos altos ingresos por razones de recaudación y de justicia social.

Sin embargo, desde la perspectiva social no es equitativo gravar más fuertemente a los de menores ingresos que a los de ingresos altos, pero esto es lo que la cuota fija logra en los niveles más bajos de ingresos de las microempresas, rangos en los que quizás opera una alta proporción de ellas. Tampoco es equitativo gravar a microempresarios o a cualquiera otro contribuyente de igual nivel de ingresos con tasas diferentes, como lo hace la "regla del 10\%".

Quizás una de las injusticias más inquietantes del régimen impositivo de la microempresa es ser más oneroso que el que enfrentan compañías extranjeras que operan en asociaciones de participación con empresas estatales cubanas. Los contrastantes regímenes tributarios se resumen en el cuadro 6. En este cuadro se aprecia claramente que mientras las empresas extranjeras en sociedad reciben un tratamiento tributario bastante normal en comparación con los estándares internacionales, ese trato es mucho más favorable que el que reciben las microempresas de propiedad y orientación locales.

El régimen impositivo para las microempresas quebranta la lógica de la asignación de recursos y, por lo tanto, reduce los estándares de vida. En primer lu-

CUADRO 6

Cuba: Comparación entre el régimen impositivo para la microempresa cubana y aquel para las empresas extranjeras que operan en asociaciones de participación

\begin{tabular}{lll}
\hline & Sector de la microempresa & Asociaciones de participación \\
\hline Tasas impositivas efectivas & $\begin{array}{l}\text { Pueden exceder del 100\% de los } \\
\text { ingresos netos } \\
\text { Base impositiva efectiva }\end{array}$ & $\begin{array}{l}30 \% \text { de los ingresos netos (50\% para la } \\
\text { minería y el petróleo) }\end{array}$ \\
Posibilidad de deducir la inversión & No deducible del ingreso imponible & $\begin{array}{l}\text { Ingreso neto, deducidos los costos } \\
\text { imponible por completo del ingreso }\end{array}$ \\
Tributación de cuota fija & Pagos necesarios anticipados de cuota fija & No hay \\
Devolución de pagos en exceso & Sin devolución & No corresponde \\
"Vacaciones" tributarias & No & Sí \\
Repatriación de utilidades & No & Sí \\
\hline
\end{tabular}

Fuente: Análisis del autor. 
gar, los gravosos niveles de tributación implícitos en el régimen impositivo llevan a los empresarios a cerrar o, en algunos casos, a restringir su propia producción para no caer en tramos de impuestos más altos. En ambos casos se reduce el volumen de bienes y servicios producidos en el sector y se elevan los precios. En segundo lugar, el régimen impositivo de la microempresa restringe la entrada al sector, limitando la competencia, reduciendo la producción y elevando los precios. En tercer lugar, el movimiento de las microempresas a la clandestinidad o la resistencia de muchos trabajadores por cuenta propia a registrarse y pagar impuestos se traduce también en ineficiencias del uso de recursos. Esas empresas tienen que operar en una escala muy pequeña y esconderse continuamente. Esto probablemente reduce la calidad de sus productos y sube sus precios en comparación con las empresas que operan legalmente (tomando en cuenta que los impuestos se transfieren a los precios de las microempresas legales).

Al bloquear la entrada de nuevas microempresas y promover su salida, el régimen impositivo reduce también el empleo productivo y la generación de ingresos. El desempleo abierto llegaba a 6.8\% en 1996, mientras que el desempleo abierto equivalente del "subempleo" se estimaba en $27.3 \%$ para el mismo año (CEPAL, Sede Subregional de la CEPAL en México, 1997, p. 378). Este último valor resalta la pérdida para el país por subutilización del trabajo.

Un resultado sorprendente del régimen impositivo de la microempresa es la discriminación que resulta contra la actividad económica orientada al mercado interno o el valor agregado interno. Las microempresas tienen poco o ningún acceso a insumos importados, salvo los que se adquieren de materiales reciclados o de compras en las tiendas de dólar o a vendedores especiales de insumos del Estado. En 1998, el tipo de cambio efectivo para ellas era de aproximadamente 20 pesos por cada dólar de insumos importados (más impuestos, normalmente de 140\%). A las empresas del sector estatal, un dólar de insumos importados les cuesta sólo un peso, cuando la importación ha sido aprobada por la autoridad de planificación. Esto significa que las empresas del Estado acceden a importaciones más baratas que las microempresas. En consecuencia, frecuentemente las microempresas utilizan insumos de origen local en mayor proporción que las empresas del Estado. Como ejemplo cabe señalar los restoranes privados, donde cerca del $100 \%$ de todos los insumos son de origen cubano, frente a las cadenas estatales de comida rápida como "Burgui" (imitación del Burger King) que importan casi todo: mesas, papas, hamburguesas, pollos, bandejas, vasos de papel, y muchos materiales especiales de construcción. El régimen impositivo actual, al discriminar contra la microempresa, discrimina contra el valor agregado interno y a favor de las empresas estatales, que hacen uso más intensivo de las importaciones.

\section{Consecuencias para la viabilidad del sistema impositivo}

El régimen impositivo para la microempresa tiene algunas consecuencias importantes en el funcionamiento y viabilidad del sistema tributario general, pues se traduce en menores recaudaciones en comparación con un régimen impositivo normal:

i) Como las tasas de impuesto efectivas son altas para la microempresa con mayores niveles de compras de insumos, el cierre de algunos negocios significa pérdida de recaudación.

ii) Cuando las microempresas enfrentan tasas de impuestos efectivas elevadas, algunas abandonan la operación legal e ingresan a la economía clandestina.

iii) Debido a que el nivel efectivo de la tasa marginal es tan alto, cuando se aplica a microempresas con mayores niveles de compra de insumos, éstas tienen el aliciente para subdeclarar sus ingresos brutos, produciendo pérdidas en la recaudación fiscal.

iv) Cuando microempresarios potenciales, enfrentados a impuestos de cuota fija elevados, piensan en establecer una microempresa nueva o volver a registrar una establecida, algunos pueden preferir la clandestinidad o el cierre de su negocio.

La apreciación de lo gravoso e injusto que es el régimen impositivo para la microempresa se ha traducido en altos niveles de evasión. Más aún, la sobrevivencia de algunas microempresas depende de la evasión, especialmente si no son capaces de trasladarse a la economía clandestina ya sea por su ubicación o perfil incompatible con ese tipo de operación. Algunas microempresas pueden subdeclarar sus ingresos.

Por su carácter y la evasión que genera, el sistema carece de credibilidad y respeto. En lugar de conducir al desarrollo gradual de una cultura tributaria en la que las personas voluntaria y honestamente pagan sus impuestos, el sistema ha provocado el hábito del engaño. En alguna medida esto formaba parte de las 
estrategias de sobrevivencia en las difíciles circunstancias de fines del decenio de 1990. La naturaleza del régimen impositivo lleva a pensar a algunos que la evasión tributaria no atenta contra la ética, aunque sea ilegal.
A largo plazo, puede ser difícil cambiar la actual actitud de evasión tributaria por una de cumplimiento y podría seguir siendo un problema aun después que se estableciera un régimen impositivo razonable para la microempresa.

\section{VI}

\section{Recomendaciones de política}

La introducción de cambios en el régimen impositivo podría reducir o eliminar algunos de sus efectos más dañinos para la microempresa. Algunos de esos cambios son simples y podrían aplicarse rápidamente. Otros son más complicados y podrían tardar más en dar resultados positivos.

\section{Recomendación 1:}

Establecer una base impositiva normal

El primer cambio podría ser establecer el ingreso neto en lugar del ingreso bruto como base impositiva. Esto significa abolir "la regla del 10\%", que restringe la deducción permisible del ingreso imponible a un máximo del $10 \%$ del ingreso bruto. Con ello mejoraría la equidad del sistema y se terminaría la discriminación contra las microempresas cuyas compras de insumos exceden el 10\% de su ingreso bruto. Al hacerse de esta forma más equitativo el régimen impositivo, la evasión se reduciría y se facilitaría la recaudación. Este cambio permitiría una expansión de la producción de las microempresas que dependen en proporciones mayores de la compra de insumos.

\section{Recomendación 2:}

Eliminar los pagos anticipados de cuota fija

La eliminación de los pagos de cuota fija mensuales tendría una variedad de resultados positivos. Removería la barrera de entrada a nuevas empresas, aumentando su número, intensificando la competencia, elevando la producción y reduciendo los precios en el sector. A su vez esto llevaría a acrecentar la recaudación tributaria. Ella aumentaría en la medida en que más microempresas ingresen al sector y salgan de la clandestinidad al eliminarse el alto costo, el riesgo y la incertidumbre que genera la cuota fija. Más aún, al eliminarse tales pagos desaparecerían también algunas de las inequidades más obvias del régimen impositivo. Ya no sería regresiva la incidencia del impuesto en los tramos de ingresos medio y bajo. Ya no existiría la no recuperabilidad de los impuestos pagados en exceso. La corrección de estas dos inequidades ayudaría a restaurar la fe en el régimen impositivo, a facilitar su cumplimiento y a reducir la evasión tributaria.

\section{Recomendación 3:}

Crear un clima de confianza en el sistema tributario En la actualidad el régimen impositivo se considera injusto e irracional, de modo que se justifican el engaño y la evasión, que parecen necesarios para sobrevivir. Por lo tanto, serían deseables cualesquiera otras políticas que contribuyeran a crear un clima de confianza en el sistema tributario. Algunos de estos cambios podrían incluir penalidades financieras razonables para la evasión, así como la devolución de los pagos excesivos a los microempresarios. La vuelta a la legalidad de algunas de las actividades económicas que antes ingresaron a la clandestinidad o permanecieron en ella, contribuiría también a la mayor equidad del sistema al reducir el número de microempresas no registradas capaces de evadir los impuestos totalmente.

\section{Recomendación 4:}

Bajar las barreras de entrada al sector de la microempresa

Otra serie de cambios dice relación con el gran número de normas y reglamentos que se mencionan en la sección III. Ellos fueron diseñados para contener el avance del sector, limitar sus ingresos y, quizás, para dar protección a algunas empresas del sector estatal. Este cúmulo de políticas estimula la clandestinidad de las microempresas, con las muchas consecuencias nefastas que se han analizado. La solución, sin embargo, no es imponer más reglas. Por el contrario, sería probablemente más sensato bajar las barreras de entrada al sector legal de la microempresa. Esto significaría eliminar muchas restricciones, permitiendo a la mayo- 
ría de los solicitantes ingresar al sector. Implicaría cambios en la estructura de incentivos, que hoy alienta a las microempresas a permanecer en la economía clandestina o las lleva a cerrar.

Si se bajan las barreras de entrada y se cambia la estructura de incentivos para no penalizar la legalidad, el número de microempresas subirá. Con mayor com- petencia en el sector la producción aumentará y los precios bajarán. El nivel de ingreso medio de los microempresarios se acercará al promedio nacional. El empleo en el sector debería crecer aunque tendría que disminuir en la economía clandestina. Por último, el volumen de impuestos efectivamente recaudados por el sistema tributario debería aumentar.

\section{VII}

\section{Resumen y conclusiones}

El régimen impositivo de Cuba para la microempresa tiene varios defectos que lo hacen inequitativo, deterioran la eficiencia de la asignación de recursos en la economía y reducen su eficacia para recaudar impuestos.

Los problemas derivan principalmente de la "regla del 10\%" y del carácter y monto de los impuestos de cuota fija que deben pagarse cada mes cualesquiera sean los ingresos. Este análisis ha mostrado que la incidencia real del impuesto es mucho más alta que la escala impositiva oficial cuando los costos de producción superan el $10 \%$ del costo máximo deducible. En las microempresas con compras de insumos en el rango del $60 \%$, la tasa impositiva marginal efectiva sobre el ingreso neto real (no el ingreso bruto menos el 10\% máximo permitido) puede alcanzar niveles superiores al $100 \%$. Más aún, los pagos anticipados de cuota fija son de hecho tasas impositivas marginales del $100 \%$ en los niveles iniciales de ingreso. Luego, la tasa impositiva marginal cae a $0 \%$ hasta que el nivel de ingreso imponible alcanza el punto donde los impuestos devengados según la escala impositiva igualan al pago de cuota fija. Esto genera un patrón de tasas impositivas marginales y promedios decrecientes en los tramos de ingresos medios y bajos, es decir, el impuesto en estos tramos es regresivo. Las tasas impositivas en la escala oficial se hacen excesivas para la gran mayoría de las microempresas que operan en la economía del peso y no del dólar.

Desde el punto de vista de la equidad, el régimen impositivo discrimina contra aquellas microempresas cuyas compras de insumos exceden el $10 \%$ de sus ingresos brutos. Es regresivo en cuanto las tasas de impuesto son más altas para las microempresas de ingresos más bajos. Discrimina contra los potenciales entrantes frente a las empresas establecidas porque aquellos deben pagar impuestos de cuota fija anticipados aun antes de generar ingresos. Gran parte del sector de la microempresa enfrenta además una carga tributaria más pesada que las empresas extranjeras en sociedades de participación.

Desde el punto de vista de sus efectos sobre la eficiencia en el uso de recursos en la sociedad cubana, el régimen impositivo tiene resultados desafortunados. Restringe la entrada de nuevas empresas al sector y lleva a otras a la quiebra, reduce la producción, eleva los precios para los ciudadanos cubanos, disminuye el empleo en el sector y probablemente contrae la generación de ingresos. Discrimina contra el valor agregado interno en el sector de la microempresa cuyos insumos son casi todos de origen local, frente al sector estatal, que paga menos impuestos, depende en alto grado de los insumos importados y puede repatriar utilidades.

Aunque el régimen impositivo recauda impuestos de las microempresas, hay diversos efectos que en realidad disminuyen el volumen de lo recaudado. Primero, la modalidad de pago de impuestos de cuota fija y las altas tasas impositivas que afectan a quienes compran insumos que exceden el $10 \%$ de sus ingresos brutos empujan a las empresas a la clandestinidad o a abstenerse del registro formal. El tamaño de la economía clandestina es inmenso, como lo es la pérdida de recaudación. La naturaleza del régimen impositivo ha dado origen a una cultura de evasión y de incumplimiento de las obligaciones.

También se presentan algunas sugerencias encaminadas a mejorar el sistema impositivo para la microempresa. Primero, debería establecerse una base impositiva normal eliminando la "regla del 10\%" y el ingreso imponible debería ser el ingreso bruto menos los costos efectivos de producción. Segundo, debería abolirse el pago anticipado de impuestos de cuota fija. 
Tercero, debería desarrollarse, a largo plazo, el acatamiento del régimen impositivo, haciéndolo tan justo y razonable como sea posible. Y cuarto, deberían eliminarse las barreras artificiales generadas por las políticas a la entrada de nuevas microempresas. También sería necesaria una administración tributaria más eficaz para prevenir abusos en una modalidad de "deducción de costos del ingreso imponible" y en ausencia de un pago de impuestos anticipados de cuota fija.

Aunque en general el sector de la microempresa debe pagar su cuota de impuestos, el régimen impositivo que se aplique no debe ser más gravoso que el que rige para las sociedades de participación y las empresas extranjeras, y debe ser equitativo entre las microempresas. Un régimen impositivo bien diseñado para éstas ayudaría al sector a desempeñar un papel más útil en la economía cubana en lo relativo a empleo y generación de ingresos y a la producción de bienes y servicios necesarios a precios relativos más bajos. Podría también generar mayor recaudación que el actual sistema que empuja a las microempresas a la clandestinidad y a la evasión tributaria.

(Traducido del inglés)

\section{Bibliografía}

Castro, Fidel (1997): Speech of April 4, 1997, Granma International, La Habana, 23 de abril.

CEPAL (Comisión Económica para América Latina y el Caribe), Sede Subregional de la CEPAL en México (1997): La economía cubana: reformas estructurales y desempeño en los noventa, México, D.F.

CEE (Comité Estatal de Estadísticas) (1998): Anuario estadístico de Cuba, La Habana.

Cuba, Gobierno de (1993): Acerca del ejercicio del trabajo por cuenta propia, Decreto-Ley, $N^{\circ} 141$ del Consejo de Estado, La Habana, 8 de septiembre.

Del Barrio, E. (1998): Sin extremismo, pero con toda firmeza, Granma, La Habana, 12 de noviembre.

Gaceta oficial (1997): De las contravenciones personales de las regulaciones del trabajo por cuenta propia, Decreto-Ley $\mathrm{N}^{\circ} 174$, La Habana, 30 de junio.

Lee, S. (1996): Trabajo por cuenta propia: una reflexión necesaria, Granma, La Habana, 13 de septiembre.

Mayoral, M. J. (1995): La ilegalidad no tiene futuro, Granma, La Habana, 14 de febrero.
(1997): Debate sobre el trabajo por cuenta propia en la capital, Granma, La Habana, 14 de abril.

Ministerio de Finanzas y Precios (1996): Declaración jurada. Divisas, Instrucción $\mathrm{N}^{\circ} 11$, La Habana.

Ministerio de Trabajo y Seguridad Social/Ministerio de Finanzas y Precios (1995): Resolución conjunta N 4, Granma, La Habana, 14 de junio.

ONAT (Oficina Nacional de la Administración Tributaria) (1997): Declaración jurada. Impuesto sobre ingresos personales moneda nacional, La Habana.

Ricardo, R. (1998): Continúa enfrentamiento por ilegalidades en la vivienda, Granma, La Habana, 14 de febrero.

Ritter, A. (1998a): Entrepreneurship, micro-enterprise, and public policy in Cuba: Promotion, containment, or asphyxiation, Journal of Inter-American Studies and World Affairs, vol. 40, $\mathrm{N}^{\circ} 2$, Miami, University of Miami, School of International Studies.

(1998b): Interviews with shoemakers, artisan workers, taxi operators, carpenters, house repairmen, "tricycletistas," restaurant operators, and other micro-entrepreneurs, La Habana, febrero, mayo y noviembre, mimeo. 